\title{
Reclaiming Feminist Futures: \\ Co-opted and Progressive Politics in a Neoliberal Age
}

\author{
Catherine Eschle, University of Strathclyde, Glasgow \\ Bice Maiguashca, University of Exeter, Exeter
}

\section{Introduction}

2009 saw the publication of three high-profile feminist texts: Hester Eisenstein's book, Feminism Seduced; Nancy Fraser's article, 'Feminism, Capitalism and the Cunning of History'; and Angela McRobbie's anthology of essays, The Aftermath of Feminism. Asserting that feminism has not simply failed to challenge neoliberal capitalism, but has rather helped strengthen its hegemony, these texts crystallise a longstanding anxiety in contemporary feminism about the general trajectory of the movement (see also Eisenstein, 2007; Power, 2009) and, in particular, its proclivity towards institutionalisation, on the one hand (e.g., Lang, 1997; Martin, 1997), and preoccupation with culture, identity and difference, on the other (e.g.,Benhabib, 1994; Nussbaum, 1999).The three texts by Fraser, Eisenstein and McRobbie thus can be seen as exemplars of the latest instantiation of an ongoing feminist concern about the decline and depoliticisation of a previously vigorous and emancipatory collective struggle.

While we share the three authors' apprehension about the neoliberal project and its capacity to co-opt feminist politics, we think that their work merits critical interrogation for two reasons. To begin with, their particular interpretations of co-optation induce in us a sense of cognitive dissonance to the extent that they render invisible the particular feminist struggles on which we published recently (AUTHOR REFERENCE). Rooted in field work on feminists at the European and World Social Forums in Paris, London, Mumbai and Porto Alegre between 2003 and 2005, our book sought to map the wider terrain of what we called feminist 'anti-globalisation' activism. The fact that such activism is explicitly opposed to neoliberalism, among other things, raises questions for us about empirical overgeneralisation and unwarranted pessimism in the writings by Fraser, Eisenstein and McRobbie.

We have an additional reason for engaging with these three texts, however, which takes our analysis in a different direction. On our reading, they not only reiterate a narrative of the downward trajectory of feminism, but also, to varying degrees, expound on how feminism could be reclaimed from the clutches of neoliberalism. Their attention to what we will call here the 'progressive' potential of feminism is undoubtedly more marginal, but we believe it underpins the analyses of co-optation that are being put forward and also that it offsets the pessimism therein by proffering hope for an alternative future for feminism and for a more feminist future for us all. The question of what exactly constitutes progressive feminist politics in a neoliberal age thus lurks in the shadows of these texts - and seems to us a crucial question, deserving of more sustained critical attention.

In this article, we argue that the proleptic imaginings in the three pieces by Fraser, Eisenstein and McRobbie all, in different ways, constitute a circumscribed vision of a more progressive future for feminism - one that is at best unconvincing and at worst injurious, functioning as it does to dismiss contemporary feminism by comparison. We develop this argument in four steps, mapping on to the four parts of the article. In the first part, we outline the respective stories of co-optation that are on offer here before bringing to the fore the conceptions of progressive feminism underlying them. In the second part, we develop a critique of the 
substantive claims contained therein about progressive feminist politics, focusing in turn on who is named as the agent or bearer of progressive politics, the agenda they are urged to pursue, and the practices to which they are expected to commit. In the third part, we continue our critical scrutiny by turning to the conceptual scaffolding erected by our authors to capture and defend their exemplars of progressive politics. The fourth and final part of the paper seeks to disentangle and refine this conceptual language in an effort to open up questions of who can enact progressive politics, to what end and how. In this way, we seek not only to critique the narratives of Fraser, Eisenstein and McRobbie, but also to begin work on an alternative framework for conceptualising progressive politics and thereby to reveal a contrasting substantive vision of feminism reclaimed.

\section{Tales of Feminism Lost and Found}

As a necessary first step in establishing the notions of progressive feminist politics that underpin the arguments of our three authors, we begin by giving some space to the accounts of co-optation that are, after all, front and centre in their texts - and that are fleshed out in very different ways.

Eisenstein's Feminism Seduced is historical-sociological in its approach, broadly Marxist in its orientation, and focuses mostly on the US. Its primary aim is to trace the ways in which 'hegemonic mainstream' feminism has served, unwittingly, to legitimise the ideas and practices of corporate capitalism. In Eisenstein's view, it has done so, in part, by undermining labour and 'social feminist' struggles to protect the distinct needs and interests of women, by, for example, securing the family wage. Instead, by pushing for the full integration of women into the capitalist economy on the same basis as men - in the name of professional advancement and equity in the workplace - liberal feminist campaigners provided a convenient justification for the neoliberal elite to lower wages and cut welfare programmes (Eisenstein, 2009, pp.39-72). In addition to directing their energies towards the interests of the educated middle classes, these campaigners failed to address racial inequalities and thus contributed to a fracturing of women's solidarity along race as well as class lines (2009, pp.73-106), with the result that the most oppressed women in society have been left to struggle alone in the neoliberal era $(2009$, p.132). Finally, Eisenstein shows how the diffusion of neoliberalism to the Global South was made easier by the active collaboration of professionalised, institutionalised 'gender experts' who, working in the context of nongovernmental organisations (NGOs), willingly took over the welfare functions of the state. In so doing, Eisenstein suggests, they steered 'grassroots' organizations away from 'radical' reforms and, thereby, demobilised popular struggle (2009, p.162). ${ }^{1}$

While acknowledging Eisenstein as an influence, Fraser's article 'Feminism, Capitalism and the Cunning of History' offers a more schematic and social-theoretical overview of recent developments. Her main argument is that feminism as a 'transformative political project' has remained 'largely stillborn' $(2009$, p.107), in part because of feminist complicity in capitalist processes. In this regard, she outlines four detrimental shifts in feminist analysis and politics during the 1980s. First, second-wave feminist understandings of justice predicated on an integrated view of both economy and culture have given way to a narrow preoccupation with the latter and thus with the pursuit of recognition for identity differences (2009, pp.103-4, 108-9). Second, the critique by second wave feminists of the androcentrism of paying a family wage to male heads of households has segued into an aspiration for the full incorporation of women into the market economy. For Fraser, as for Eisenstein, this is problematic as it effectively means 'the dream of women's emancipation is harnessed to the 
engine of capitalist accumulation' (2009, pp.110-111) — and, by implication, the divorce of feminism from the left $(2009$, p.104). Third, the opposition mounted by second-wave feminists to the patriarchal state has been tamed; indeed the takeover by feminist NGOs of the provision of public services in the global south has effectively meant abandoning the struggle for a responsive state policy (2009, p.111-112). Finally, the rise of transnational feminist organising has functioned in Fraser's view to reinforce this dynamic and to further disembed feminism from grassroots struggles (2009, pp.112-113). The overall result is that neoliberal capitalism has succeeded in producing a spectral version of feminist discourse, which it uses to its own ends (2009, p.114).

Last but not least, McRobbie's book The Aftermath of Feminism focuses specifically on popular culture and on the UK context. Influenced not only by Marxism but also by diverse sources of poststructuralist theory, McRobbie argues that the integration of young women into education and the labour market in an era of neoliberalism has involved the 'success' of a kind of 'faux-feminism' whereby political elites and popular cultural forms have instrumentalised and 'taken into account' feminist principles of equality and freedom (2004, p.510; 2009, pp.1-2, 12-15, 72-83). For McRobbie, the apparent successful attainment of feminist goals in the form of the individualisation of women has occurred in tandem with the disavowal of feminism as a movement, the result of a double-edged process in which, on the one hand, feminism is presented by political elites and in popular culture as a monstrous stereotype, making it deeply unpalatable to young women, while, on the other, femininity is re-entrenched in highly racialised, sexualised and consumerist ways. This latter point is at the heart of McRobbie's analysis: she develops an innovative conceptual language to help her document in rich detail the ways in which the embodied subjectivities of young women are violently disciplined to be 'spectacularly feminine'. The 'illegible rage' that results is manifested according to McRobbie in a range of psychic disorders, from anorexia to suicidal depression (2009, pp.94-123). Individual women must now cope with the contradictions of neoliberalism alone, given that 'progressive social movements' have become increasingly 'disarticulated' from each other (2004; 2009, pp.24-53) and, what is worse, that certain strands of contemporary feminism - specifically 'gender mainstreaming' within the state and so-called 'third wave' celebrations of consumerist femininity - are actively reinforcing the neoliberal agenda (2009, pp.152-8).

As should be clear, these accounts of co-optation are rooted in divergent scholarly traditions. Although all three are influenced by debates within critical theory, broadly construed, both Fraser and Eisenstein are wedded to a socialist/Marxist feminist analysis of gender oppression which centralises the socio-economic realm as the key context for this subordination and points to the role of wage labour as the primary mechanism by which it is sustained. This lies behind their indictment of struggles against gendered violence, for instance, as paying insufficient attention to economic causal dynamics (Eisenstein, 2009, pp.73-106). It is also the reason why they express impatience with what they see as a turn to culture and identity within feminism, a trend that both perceive to be a distraction from the main task of critiquing capitalism (Fraser 2009, p.108; Eisenstein 2009, p.2). In contrast, McRobbie, who represents the kind of feminist cultural theorist cum poststructuralist that both Fraser and Eisenstein seem to warn against, highlights culture as an important site of individual subjectification in an era of neoliberal governmentality and, thereby, as an appropriate focus of analysis and critique.

Notwithstanding their differences in terms of descriptive detail and scholarly lineage, however, the analyses offered by these authors converge in important ways. To begin with, 
they are all concerned with a common collective subject, that is, the feminist movement writ large. In each text, feminism is depicted not as a particular ideological or country-specific strand of activism, but as a collective agent, however delineated, with a global trajectory. Thus Eisenstein tracks the projection of liberal feminist tropes from the heartland of the US to countries in the Global South, while Fraser makes it clear that her claims about feminism transcend the specificities of the US women's movement and encompass 'second wave feminism as a whole' understood as a 'epochal social phenomenon' $(2009$, p.97). And although McRobbie explicitly situates her analysis in the context of the UK, (see Dean, 2010, p.146), the generalised, abstract quality of her argument, marked as it is by undifferentiated pronunciations about the 'aftermath of feminism' as a whole, implies that the dynamics she outlines are in no way unique to the British movement.

Moreover, the stories outlined above of the co-optation of this global feminist movement share three features in common. First, feminism is depicted by Fraser, Eisenstein and McRobbie as having shifted from an internally coherent and externally well-connected movement to one that has fractured along fault-lines of gender, class and race and become isolated from erstwhile allies, particularly those on the left. Second, a corresponding reorientation of the feminist agenda is identified. Whether now preoccupied with questions of identity (Fraser), professional advancement (Eisenstein), or newly sexualised renditions of femininity (McRobbie), today's feminists, according to our authors, lack the critical edge they used to have when they centralised capitalism as their subject of analysis and critique. Third, all our authors assume that feminist practices have become ineffective at best and depoliticised and complicit with capitalism at worst. Two types of practices come into relief as particularly problematic. On the one hand, all three authors are sceptical of the efficacy of feminist politics on the terrain of culture and identity/difference, with even McRobbie admitting to the naïvety of her earlier writings extolling the virtues of women's magazines as a possible way to create and sustain alternative feminist subcultures (McRobbie 2009, p.5). On the other, they all see institutionalised feminist practices - whether in the form of NGO service provision activities or 'gender mainstreaming' — as compromised by their association with neoliberal elites and their 'professional ethos of depoliticized expertise' (Fraser, 2009, p.105).

Taken together, these three claims about the changing character of the feminist movement, agenda and practices contribute to a picture of it as comprehensively 'undone'. All is not lost, however. For in the closing stages of the texts under consideration, two quite distinct visions of a more progressive version of feminism emerge, one based on retrieval and the other on reinvention.

Starting with the former, Fraser and Eisenstein both seek 'a revival of the socialist feminist tradition' and its elevation to a 'major role' in contemporary feminist politics (Eisenstein, 2005, p.488). This would entail, most fundamentally, the 'reposition[ing] of feminism squarely on the Left' (Fraser 2009, p.116) or, as Eisenstein puts it, 'mending the break with the Left' (2009, p.202). To achieve this task feminists are entreated to critically re-engage with capitalism, understood as an inherently exploitative social system. Within this context, both authors argue for a more integrative analysis of power relations that brings the interconnections between gender, race and class back into the picture. For Eisenstein, 'the experience of women of color and working class women needs to become the basis for agenda setting in future activism' (2009, p.211); in Fraser's more abstract language, this translates into to a call for the reintegration of the cultural and socio-economic elements of gender oppression and correspondingly the rebalancing of struggles for recognition and 
redistribution. In addition, both authors argue that a feminist struggle against capitalism must make the values and relationships associated with caring for others central to its agenda. In this vein, Fraser asserts the need to campaign for 'a way of life that decentres waged work and valorizes uncommodified activities, including carework' for both women and men (2009, p.116) and Eisenstein, more forcefully, ends her book with a call for 'a return to maternalism, but writ large', such that the 'qualities of nurturance and care' traditionally associated with motherhood 'now need to be the domain of society as a whole' and to underpin political life (2009, p.228).

Turning to the vision of reinvention, McRobbie also yearns for the socialist feminists of the past and their 'relentless critique of capitalism' $(2009$, p.48). Despite evoking this spectre throughout her book, however, she turns ultimately to a very different type of agency, what she calls a 'new minoritarian politics' (2009, p.164). Drawing on the 'affirmative' reflections of philosopher Rosi Braidotti, McRobbie describes a process of personal transformation and of 'becoming other' which takes the subject beyond liberal, heterosexist norms and enables 'radical escapist mutations' (2009, p.164). In the last few pages of her book, she attempts to put more sociological flesh on the bones of this idea by presenting her young female MA students as open to such a process of transformation, especially in the context of the feminist classroom. Pointing to the possibility of instilling in these students an ethos of 'radical multiculturalism and classroom democracy' by means of a critical pedagogy, she claims that such a process 'should be about more than the transmission of knowledge', instead engaging students as equals and allowing them to bring their personal histories into dialogue with the postcolonial and feminist sources that they read (2009, p.166). As McRobbie concludes, '[p] edagogy and learning have become vital spaces of encounter, and new kinds of contact zones where histories, including gender histories, which otherwise have been subject to enforced forgetting have perhaps a small chance now of being written' $(2009$, p.170).

In sum, Eisenstein, Fraser and McRobbie offer rich narratives of feminism lost and found, of a co-opted present and a more optimistic feminist future. Whether seeking to retrieve from the past what has been lost or to invent something entirely new, these authors refuse to accept that the collapse of feminist potential that they outline is terminal, instead wresting hope, however tenuous, from the wreckage. While we think this a laudable move, we will go on to show how these two depictions of progressive feminist politics are problematic in both substantive and conceptual terms, functioning to warp the analysis of co-optation with which they are intertwined.

\section{Critiquing Empirical Claims about Progressive Feminist Politics}

We begin our critique by subjecting to scrutiny the substantive claims evident in our authors' narratives of retrieval and reinvention regarding who might be the rightful bearer of progressive politics, of what a progressive political agenda should consist, and how that agenda must be pursued.

In terms of the favoured agent of change, all three writers share what could be described as a nostalgic attachment to the socialist feminism of the past, with Fraser and Eisenstein arguing for its revival and McRobbie lamenting its demise. Now while we have no issue with nostalgia per se playing a role in the articulation of a progressive politics (see Bonnett, 2010), nor with the notion that socialist feminism may be a good place to start that endeavour, we underline two interconnected problems with how this plays out in all the texts under discussion. 
First, socialist feminism is romanticised, presented as an ideal-type rather than as a concrete, internally complex, historically specific political project. McRobbie has been criticised, rightly, for mobilising socialist feminism as a kind of 'shortcut label', never describing exactly what it was or why it might have declined in popularity (van Zoonen, 2010, pp.1701). Perhaps she might be excused this, given that she does not rely on socialist feminism for her progressive politics of the present. But Fraser and Eisenstein do, and here too socialist feminism remains elusive, glimpsed only through rose-tinted spectacles. Fraser's account, for example, contains some historical inaccuracies, eliding as it does socialist feminism in the 1970s with black and anti-imperialist feminism and attributing to all three an intersectional analysis that was actually pioneered by black feminists (2009, p.103; e.g., Combahee River Collective, 1977). In Eisenstein's book, the issue is rather one of absence: socialist feminism is explicitly summoned in an earlier article (2005, p.488) and implicitly invoked in the book in calls to 'put socialism back on the agenda', but barely features in the accompanying analysis of the triumph of mainstream liberal feminism over what Eisenstein calls 'social feminism' and 'labor feminism' (2009, pp.40-54). Connectedly, Fraser and Eisenstein neglect internal debates and conflict among socialist feminists. This can be seen in their discussion of the revaluing of care work, positioned by both authors as central to a socialist-feminist revival and especially important to Eisenstein's progressive vision, but which has long been subject to high-profile contestation among socialist feminists and beyond in ways that surely merit some consideration. ${ }^{2}$

The second problem - the converse of the first - is that contemporary strands of feminism are assessed in light of this romanticised ideal and found wanting. So, for example, McRobbie's sweeping dismissal of 'third wave' feminism as an apologia for capitalism ignores the expansive literature on the internal contestations and contradictions of this feminist trend (e.g., Dean, 2009; Henry, 2004; Snyder, 2008). In parallel, Eisenstein's depiction of the rise of poststructuralist feminism in the 1990s ignores, among other things, the fact that many of the thinkers involved - like McRobbie herself - come out of a socialist feminist tradition. To use an argument made by Cynthia Weber (1994) in a different context, all three authors in their different ways are disciplining feminism from an assumed position of authority and in accordance with their own purposes, elevating socialist feminists as the 'good girls' of the past and thereby denigrating, variously, liberal feminists, cultural theorists, poststructuralists or the third wave as the 'bad girls' of the present. In so doing, our authors run the risk of reifying differences among feminists, failing to 'appreciate the connections' and hard-won alliances that also flow through 'the feminist body as a whole' (Weber, 1994, p.347).

The limitation of their vision of the agent of progressive politics, however, goes beyond their shared tendency to discipline contemporary feminism in light of an idealised social feminism. In terms of Fraser and Eisenstein, an additional problem arises with their insistence that feminism and 'the left' be reintegrated. Indeed, in our view, both these authors seriously underestimate the tensions between these two political forces, historically and today. Although Eisenstein acknowledges the much-documented 'unhappy marriage' between them throughout the nineteenth and twentieth centuries (2009, pp.203-206) and Fraser notes the critique by second-wave socialist feminists of the androcentrism of their Left comrades (2009, p.10), both analysts assume that such obstacles can be overcome. Fraser simply asserts the necessity of reunion while Eisenstein's prescriptions for 'healing' (2009, pp.206-209) between the left and feminism, based on the former taking feminist forms of solidarity and aspirations more seriously, and the latter going 'beyond anger', seem to us to be set out more 
in hope than in realistic expectation. Even more worrisome is the implication that the progressive character of socialist feminism is secured by its adherence to the socialist/Marxist/left side of the equation. Surprisingly, for Fraser and Eisenstein, socialist feminism appears to acquire its critical bite and realise its emancipatory promise only insofar as it is socialist or left, not feminist. Thus, feminism qua feminism is positioned not only as non-left, but also as non-progressive. ${ }^{3}$

Turning to McRobbie's political imaginary, the agent, as we have seen, is assumed to be the individual subject (read female student) who is depicted as capable of deep personal transformation. But McRobbie's articulation of the nature, direction and end product of this process, although evocative, remains rather inchoate and non-committal. First, she gives us no justification of why she lays all her hopes for a 'new minoritarian politics' on the role of higher education, in general and on young, middle class, cosmopolitan students from the colonial periphery, in particular. She certainly fails to explain in what sense these relatively privileged students are 'minoritarian' and why she thinks that their highly mobile, reconstituted subjectivities will be 'novel' in any way or, for that matter, progressive. Moreover, McRobbie's turn to the individual as the bearer of progressive politics seems to leave no room for the key ingredient that any collective effort at re-articulation would require, that is, inter-subjectivity. Instead, her vision of the politics of becoming seems to take for granted the individualisation of women, albeit with the self formed through encounters with others. In so doing, McRobbie seems to accept the very terms of the Faustian pact between feminism and neoliberalism that she decries, allowing that resistance in contemporary conditions can only be undertaken by individualised subjects, alone, and thus shutting out the possibility of collective political struggle now or in the future.

If the agents of progressive feminist politics proposed by these authors are problematic, so too are their agendas. With respect to McRobbie's agenda, we have already indicated that her suggestions on this topic are very schematic. Her call for a 'relentless critique of capitalism' (2009, p. 49) offers a starting point, one that is shared with Fraser and Eisenstein. But it is far less apparent how her affirmative vision of 'radical democracy' and 'multiculturalism', along with their attendant values of 'pluralism' and 'otherness', fits with this critique. In other words, even if one could foster such a radical ethos in the classroom, how would one go about translating this moment into a wider social and political project that might challenge 'our total subsumption by capital' (McRobbie 2009, p. 164)?

By comparison, Fraser's and Eisenstein's plea for the return of socialist feminism reactivates a more explicit, extensive and substantive political agenda revolving around the re-centring of a critique of capitalism, the re-integration of class, race and gender in this analysis and the revaluation of socio-economic and cultural axes of oppression so that the former is once again given its due. This call for a recalibration of feminist political priorities sounds reasonable enough. And yet there is a danger here that in their efforts to rectify an assumed skewing of feminist analysis whereby gender is privileged over class and race, and recognition over redistribution, Fraser and Eisenstein actually tip the scales in the other direction, allowing for the reassertion of class and socio-economic oppression over other forms of power and suffering. Such a hazard arises in the first place because the existence of the imbalance to which they are responding is, at the very least, contested. After all, what about the claims of Latin American feminists that they have long sought to integrate an account of class and gender oppressions (e.g.,Chinchilla, 1991)? Or what about those feminist critics who do not accept the recognition and redistribution dualism and by implication the categorisation of social movements (including feminism) on this basis (Alcoff, 2000; Butler, 
1998; Young, 1997)? It is beyond the scope of this article to adjudicate these competing claims: the point we are trying to make is simply that Eisenstein and Fraser are offering a solution to a problem that many other feminists seem unconvinced actually exists - and in this way, may be creating a new problem of their own.

A second issue with Fraser and Eisenstein's call for a recentering of the critique of capitalism is that neither scholar makes clear how socio-economic and cultural axes of oppression, or gender, race and class, can be understood as mutually constitutive within a framework that simultaneously privileges capitalism. Our anxiety on this point is that feminist contributions to the progressive agenda, rather than socialist or Marxist ones, gets lost. This worry is particularly heightened when Eisenstein asserts that 'gender, race and nationality are ultimately grounded in production relations' (Aguilar cited in Eisenstein, 2009, p.213), implying that these other axes of oppression, and the struggles they generate, are, in fact, an effect of the foundational structure of capitalism. She reinforces this impression when she intimates that the divisions between white women and women of colour in the US are primarily an issue of class, rather than race $(2009$, p.214). Fraser is not much more reassuring. Characterising capitalism as a 'social totality' (2009, p.103) and entreating feminists to make market-mediated processes the 'major focus' of their analyses critique' (2009, p.115), she does little to alleviate fears that she is rebalancing the scales in favour of production relations and the class politics that it generates.

These drawbacks with the substantive characterisations of the agent and agenda are accompanied by an almost complete neglect of political practices. Fraser, for one, tells us nothing about how her preferred political agent should act. We do get glimpses of what progressive political practice should look like from Eisenstein, who includes popular education, consciousness-raising, mass mobilisation, coalition building, union organising and neighbourhood cooperatives in her trawl through possible ways forward (2009, pp.202-27), and from McRobbie who puts forward critical pedagogy as crucial to the transformation of her students subjectivities (2009, p.166). But, in the end, rather than defend these suggestions in light of what might constitute progressive political practices in a neoliberal age, all three authors seem to assume that these practices will automatically flow either from the revival of social feminism both as an agent and agenda or, in the case of McRobbie, from the transformation of students subjectivities. Moreover, all three implicitly limit the array of possible progressive practices by strenuously denying the potential of either cultural and/or institutionalised practices. In this way, we are left to assume the nature of progressive feminist practices from what they are not.

We have shown in this section that all three of our authors have an uncritical affection for socialist feminism, whether this is mourned as the progressive agent of the past or willed back into being to carry the hopes of the present. This attachment carries with it exclusions and blind spots, for socialist feminism remains highly under-specified and indeed romanticised in these texts, as does the relationship between feminism and the left. This not only makes the desired retrieval of socialist feminism by Fraser and Eisenstein as the vehicle of progressive politics less compelling, it also allows them to skew their desired progressive agenda in ways that favour Marxism over feminism and to neglect the role of concrete political practices in bringing about this agenda. Even McRobbie, who refuses to return to the past for a saviour, is unable to fully flesh out her vision in ways that offer a convincing alternative to the socialist feminism for which she yearns. Indeed, her focus on the individual subject and educational encounters in the classroom could be said to signal an unsatisfactory retreat from collective action in the wake of socialist feminism's demise. On both accounts, 
then, socialist feminism functions as a benchmark to discipline contemporary strands of activism as insufficiently progressive by comparison. As we will go on to argue in the next section, this disciplining dynamic is sustained and made more plausible by the ways in which three interconnected concepts are deployed by these authors to undergird their proleptic imaginings.

\section{Critiquing Conceptual Underpinnings}

Fraser, Eisenstein and McRobbie all mobilise, to varying degrees and in different ways, the concepts of 'left', 'radical' and 'progressive' to characterise the kind of feminism to which they aspire. None of these terms are defined clearly and, partly as a result, our authors often use them interchangeably. This conflation, in our view, both serves to restrict their political imagination and to enable them to assert, rather than defend, their conclusions. Let us take each concept in turn.

In all the texts under consideration, the category 'left' is equated with a specific political force, namely socialism and/or Marxism. We have several problems with this move. To begin with, little detail is supplied about this agent in either historical or sociological terms. Eisenstein does discuss the Marxist tradition' briefly, referring to 'successive Marxist revolutions' and struggles, particularly in the Global South (2009, pp.203-4), but McRobbie and Fraser give us nothing at all. Just like the trope of 'socialist feminism', then, 'left' becomes another shortcut label referring to a decontextualized, generalised social actor. Moreover, this understanding of the left excludes the contribution of other strands of activism commonly associated with the term, such as social democracy or anarchism. Indeed, leftwing politics has thus been effectively, if unintentionally, policed by our three feminist authors in the same way as feminism. Finally, by assuming that left=Marxism, our authors equate the term with a specific political agenda, the salient feature of which is its anticapitalist orientation. This is a common tendency in the wider literature. ${ }^{4}$ Nonetheless, we suggest that it unnecessarily limits our understanding of the left to what it is against, leaving untouched the question of it is for.

Whereas the meaning of left is narrow and fixed, the concept of radical is more promiscuous (see Pugh, 2009, for a variety of usages). There are at least three different ways in which the term is deployed in the texts under discussion. The first refers to 'the desire to grasp and pull up the roots of an existing political arrangement' (Bonnett, 2010, p.7); such a view is shared by all three authors, but is particularly striking in the writings of Fraser and Eisenstein, with their monological conception of capitalism as the sole source of all other power relations and their attendant injustices. 'Pulling up' capitalism, it is thus implied, would bring with it an end to not only class but also gender and race. A second way in which radical is mobilised is to refer to a privileged political agent, one that exhibits 'distinctly bold forms of political commitment' (Bonnett, 2010, p.7) and/or which represents 'the people', or the 'voice from below'. For Fraser and Eisenstein this agent is represented by the left, by the socialist feminists who align with them and by working class and black women who 'identif[y] more with the grassroots' than with elites (Fraser 2009, p.105). In McRobbie's case, it is the elusive 'minoritarian subject' who is exclusively charged with the responsibility of 'invent[ing] some feminist newness' (2009, p.164). A third, although less prominent, conception of radicality at work in these texts pertains to the alleged 'purity and authenticity' of a particular set of political practices (Dean, 2008, p.284). Although all three authors clearly assume that some practices are more radical than others, (e.g., critical pedagogy for McRobbie) none of them specify why this is the case. 
Thus the term radical has multiple connotations, often deployed simultaneously, to capture variously the imperative to challenge a foundational power relation, to grant priority to a particular agent or to favour a particular practice. One difficulty here is that our authors do not make clear which understanding is in play at any one time, or think through the implications of these varying definitions. The term is instead continually mentioned in passing as if its meaning was self-evident. Another is that all three renditions of the terms are associated by our authors with the left. Thus radical is used at various points to characterise the left agenda as they define it, i.e., anti-capitalism, and the left political agent, i.e., Marxism. All these associations are simply asserted, rather than substantiated. While it may be a very common move in left-wing traditions to deploy the notion of radicalism in this way, it seems an obviously self-justificatory move to us, one that clouds the historically complex relationship of the left to varying traditions of radicalism (Bonnet, 2010, pp.6-7).

Finally, the notion of 'progressive', while invoked rather less frequently than the other two terms, nonetheless features in all three accounts. Eisenstein tells us on the opening page of her book that she is 'a progressive, a person on the left ...' $(2009, \mathrm{p} .1)$ while McRobbie uses the term to express approbation for social movements that are implicitly deemed to be on the left (e.g., 2009, p.25). Although Fraser mentions the adjective only twice in 'Cunning of History' (preferring to use the term 'emancipatory'), she has deployed it repeatedly in her earlier work to refer to struggles seeking to overturn economic inequalities and social hierarchies (e.g., Fraser, 1995). Regardless of its frequency of use, in all cases the term progressive is deployed to indicate a politics of which our feminist authors approve, that is, it is used to indicate the worthiness of a particular struggle. Thus, unlike 'left', which does have a fixed substantive meaning, and 'radical' which has multiple connotations, the term progressive plays the role of an empty signifier, that is, it has no independent, agreed-upon content, instead gaining its meaning in relation to the context in which it is used and specifically in relation to left and radical.

While the notion of progressive is often used in this substantively empty but normatively loaded way in the wider literature (Brass, 2006; Loberfeld, 2004), for us such a habit poses a problem to the extent that it exonerates scholars from justifying the normative evaluations that accompany the deployment of this term. Indeed, in much of the left literature it is enough to characterise a movement as left or radical for it also to be deemed progressive. ${ }^{5}$ But the notions of left and radical simply cannot be relied on to do the necessary justificatory work here: they do not, in themselves, tell us why a particular form of politics is worth defending.

Overall, it can be seen that the concepts of left, radical and progressive play an important role in the feminist works we have reviewed, simultaneously delineating and affirming the kind of feminist politics to which Fraser, Eisenstein and McRobbie aspire. Eliding these concepts throughout their texts allows our authors to present the reader with a fait accompli: a left politics is a radical one which, in turn, must be progressive. It is this conflation which enables our authors to construct and sustain their stories of co-optation; any feminism deemed not to be left, in the narrow sense of the term, is precluded from being radical or progressive and thereby positioned as part of the problem rather than the solution. Moreover, it allows all three authors to simply assert the normative value of their proposed feminist futures rather than defending them in either empirical or normative terms. Even more importantly for us, this conceptual circularity limits their vision of who counts as progressive and what can be included in a progressive agenda. Connectedly, it encourages the neglect of what constitutes progressive practice to the extent that left and radical are read off the agent and agenda so 
that for all intents and purposes practices enacted by a left-wing actor in the name of a radical agenda are assumed to be progressive. In the name of the more 'open future' that Fraser calls for $(2009, \mathrm{p} .113)$, we think it is necessary to revisit this conceptual vocabulary and, by redefining it, take one step towards widening the range of possible futures for feminism.

\section{Reconstructing Progressive Feminist Politics}

We shift now from critique to a more affirmative mode of analysis, seeking to establish a new starting-point for thinking about progressive feminist politics. To this end, we disentangle the notions of left, radical and progressive from each other and re-conceptualise each in turn. We then point to ways in which this alternative conceptual matrix can help us repaint the picture of progressive feminist politics.

\section{Reconceptualising Left, Radical and Progressive}

Although the left/right distinction has been dismissed as irrelevant in a post-1989 world (e.g., Bruhn, 2005; Giddens, 1994) it continues to have considerable currency. Indeed, partially in response to the retrenchment of neoliberal policies globally, there has been a wave of literature aiming to redefine the meaning of the left as well as to revive it politically (e.g., De Sousa Santos, 2006; Ellner, 2004; Thérien, 2002). Among this crowded field, for us the work of Noberto Bobbio (1996) and Steven Lukes (2003) stands out with its claim that the left is best understood as a political project animated by the 'emotive value of equality' (Bobbio, 1996, p.65). While taking historically grounded and context specific forms, this project is based on a shared moral objection to 'unjustifiable but remedial inequalities of status, rights, powers and condition' and a commitment to 'rectify' them through political action (Lukes, 2003, p.612). Thus, those on the left dream of and fight for a society of equals, a cooperative, horizontal social order in which everyone is considered of equal worth independently of their abilities, achievements and circumstances. This can be contrasted with the 'vertical' or hierarchical society supported, or at least accepted, by the right (1996, p.58). For those on the right, social inequalities are the natural expression of people's divergent capabilities and ambitions. For those on the left, however, inequality is a socially created problem, one that is sustained through 'customs, laws and coercion' (Bobbio, 1996, p. 67) and that can and should be overturned with political will and collective political action. ${ }^{6}$

Redefining the left in this way has a number of important implications for the purposes of this article. With respect to the agent, it serves to open up the range of political forces that can be seen as constituting part of 'the left' by bringing into the fold, for example, liberal egalitarianism and anarchism. In addition, this redefinition stretches the parameters of the left political agenda beyond anti-capitalism. This is, in part, due to the fact that the left is now defined as a positive project and thus requires affirmative values to be articulated and defended. It is also because diagnoses of inequality other than the critique of capitalism can now come into play.

Turning to the notion of radical, we would like to diverge from the three usages of the term outlined above and delimit its meaning to the quest for a particular kind of social change: a transformation of systemic power relations perceived to sustain ongoing injustices. By reconceptualising it in this way, we are learning from Jeremy Gilbert and Jo Littler who characterise radicalism 'as a measure of the dramatic and far-reaching ambitions for change registered by a particular political project' $(2009$, p.128). Distinguishable according to George Lawson by its 'scope, depth and effect' (2005, p.479, original emphasis), radical 
change in this sense is decidedly non-palliative in orientation, given that proponents seek to comprehensively alter one or more systems of power relations and thereby to fundamentally reshape the society in question. For us, in contrast to Lawson, such change may occur either through an abrupt upheaval over a short space of time or in an incremental, evolutionary process. What matters for our definition is not the concrete strategy through which change is achieved, but the scope of the ambition behind it.

With this conception, we are narrowing radical so that it now refers solely to a movement's intent, as captured by its agenda, rather than to a privileged set of actors or practices. This can usefully be contrasted to the three definitions of radical discussed above. On our view, political agents and/or political practices are radical only in so far as they pursue transformative goals. Moreover, a monological conception of power is not required, as there is room for multivalent analyses so long as thorough-going shifts in systems of power are sought. Finally, this way of thinking about radicalism detaches it from its automatic association with left-wing movements given that not all of them have transformative intent (liberal egalitarians, for example) and that some right-wing movements do (a fact to which popular usages of the term increasingly attest). ${ }^{7}$

Thus far we have redefined left and radical in ways that militate against their conflation. What these concepts have in common, however, is that they are descriptive-analytical in nature, denoting a movement's normative commitment to equality in the case of the left and its orientation to social change in the case of radical. While each term, therefore, gives us important information about a movement's political goals and trajectory, we are still in need of a normative-evaluative concept to help us judge and register the ethical worthiness of a particular political struggle. For us the notion of 'progressive' can serve this purpose.

So how would one begin to mount a defence of a social movement as progressive? We want to suggest that at least two imperatives must be satisfied. The first is that the analyst must engage in an explicit normative justification, bolstered by empirically informed analysis, of the movement's agenda and the agents acting on its behalf. Obviously, the substantive criteria according to which these two axes of inquiry will be evaluated will, in part, depend on the observer's political commitments. Thus for Fraser and Eisenstein, it is clear that a socialist agenda is an essential ingredient of progressive politics; while this is certainly a defensible position, it needs to be elaborated and justified. Putting our cards on the table, our sine qua non for progressive politics in conditions of neoliberalism is also a left-wing agenda, but one that incorporates the efforts of a range of egalitarians. Like our authors, we would need to justify in much more detail why this should be the case. The second imperative is that the political practices of a movement also have to be subjected to critical scrutiny. Here we are insisting that a movement cannot earn the title of progressive if its agents and agenda are worthy, but its practices unjustifiable.

But this second imperative raises a question: what criteria should be used to adjudicate a movement's practices? Here we want to tentatively propose three possible conceptual candidates that could serve as a starting point for this normative task, although we do so with the understanding that they will need to be revised in light of theoretical debate and detailed empirical, comparative research. The three principles we have in mind, all widely articulated in feminist theory and practice, are those of inclusivity, reflexivity and prefiguration. Inclusivity implies an open, engaged and generous attitude towards others. It pushes proponents to actively seek connections with others in the form of social and political alliances and to value the efforts of others to reach out to us. To this extent, it encourages 
interaction, dialogue and mutual respect (e.g., Dean, 1996; Roseneil, 1995; Taylor and Rupp, 2002). Reflexivity is an ongoing process of critical scrutiny on the part of participants in a political struggle with respect to their factual claims, their normative aspirations and their strategies. This process assumes an attitude of humility towards the process of knowledge production, seeing the resultant claims as situated, partial and open to further elaboration and recognising that they are implicated in power relations (e.g., England, 1994; Maxey, 1999; Rose, 1997). We would add that in our view, reflexivity implies that practices should be reevaluated according to their consequences, both intended and unintended. Finally, prefiguration entails a commitment to ensuring that the 'political means deployed by a movement are consonant with the aims of the movement' (Breines, 1989, p.53), or to put it differently, to 'making sure that your activist practice reflects the kind of society your movement aims to build' (Cockburn, 2007, p.178; see also, e.g., Maiguashca, 2011; Polletta, 2002). This effort to foreshadow one's desired future in the present also necessitates a focus on what Wini Breines calls the 'existential dimension' of politics $(1989$, p. 50), that is, the personal relations that sustain the activist community. In this context, individual transformation is recognised as crucial.

Having suggested three normative principles to help us adjudicate political practices, it is important to note that such criteria can only function as benchmarks and that the progressive character of any political practice, and indeed of any political agent or agenda, is not fixed or absolute, but a matter of degree. Thus, unlike Fraser, Eisenstein and McRobbie who see particular strands of activism as progressive or not, we prefer to see them as more or less so, depending on how close they come to fulfilling the normative standards set out for their practices and how defensible their agents and agendas are given the particular socio-political context in which they are located. In this way, the progressive orientation of a movement is never guaranteed and must always be earned by its participants and defended by its advocates.

\section{Rethinking the Who, What and How of Progressive Feminist Politics}

Having given the concept of progressive some content, however preliminary, we now want to outline briefly the implications of our re-conceptualisation of all three terms for imagining a desirable feminist politics in today's neoliberal world.

Let's start with the agent and agenda. Given our redefinition of the left as a project animated by the 'emotive value of equality', it should be clear, as Bobbio reminds us, that all variants of the feminist movement, whether liberal egalitarian, social democrat, socialist/Marxist or anarchist, share a commitment to overturning socially created gender inequalities, however and wherever they manifest themselves (1996, p.67). Defined in this way, feminism as a political project is inherently on the left. Indeed, in this light, the claim of our three authors that the feminist movement tout court has split from the left looks rather nonsensical, as does their assumption that, when it knocks on the door for re-entry to the left, only socialist feminists should be readmitted. Given we have already stated that we believe progressive politics today must be left in character (a position that we recognise needs explicit defence), it should be clear that we also think all strands of feminism can, at least potentially, be progressive. To say this does not mean, however, that the specific content of this left agenda should not be open to vigorous debate and, in the end, there may well be no agreement on what feminist priorities should be. In sum, while we want to acknowledge divisions within feminism, we also want to remind feminists that we have a shared project, one that is on the left, driven as it is by the desire to rectify unjust inequalities. 
If the agent and agenda of a progressive feminist politics need to be left in order to be progressive, do they also have to be radical? The answer will vary depending on the observer's political commitments. In our case, we do think that progressive politics would be best served by a radical agenda as we have defined it, that is, one intent on comprehensive systemic change. For us patriarchy, racism and capitalism operate as overlapping systems of oppression that demands a careful analysis of and thorough-going challenge to, their intersections. Others such as feminist liberal egalitarians may not agree with this diagnosis. In order to leave room for these left, non-radical agendas, we argue here that a progressive feminist politics can be radical, but does not have to be. In other words, we refuse to make the radicality of a feminist movement's agenda the barometer for feminist progressive politics, preferring to be open to the possibility that the quest for reforms within the current system can, in certain circumstances, be part and parcel of a better feminist future.

Last but not least, what does our conceptual framework mean for a consideration of which feminist practices should be part of a progressive politics? We would underline here our point that no practice should be assumed to be progressive — or not - in advance of empirical study. The implication of this position is that, pace Fraser, Eisenstein and McRobbie, cultural practices around identity/recognition as well as institutionalised practices in the form of gender mainstreaming or NGO service provision, could in principle be progressive. Indeed, this position is strengthened by the fact that our notion of radical can incorporate the kind of slow-burning, incremental change that these practices often seek to achieve. In this way, a much wider panoply of feminist activities now enters the field of vision. Take, for example, the fact that the feminist 'anti-globalisation' activists of our recent study engage in a range of practices: from mass mobilisations which seek to hold the state to account to individual personalised acts of empowerment; and from popular education and consciousness raising to lobbying, advocacy work and service provision (AUTHOR REFERENCE). Rather than dismissing some of these practices out of hand, our argument implies the need for further empirical work to see if any or all of them embody the criteria of inclusivity, reflexivity and prefiguration that we have suggested (or alternative criteria). In this way, our approach would require taking much more seriously concrete feminist activities, in all their variety, which aim to oppose neoliberalism and to build a better, more equal world for both women and men.

In sum, the question of the constitution of progressive feminist politics is, in our view, a much more open-ended one than Fraser, Eisenstein and McRobbie would lead us to believe. Drawing on an inclusive vision of the left, a narrower understanding of radical and a more explicit definition of progressive, we have sought to reveal a wider field of feminist possibilities. Finding contemporary instantiations of this feminist potential, however, will depend on detailed, comparative empirical investigation and further normative theorising, along with the effort to defend the political protagonists of any instance identified, their agenda and the political practices they enact.

\section{Conclusion}

This article has sought to respond to the lament by Fraser, Eisenstein and McRobbie for the lost potential of feminism. Decrying the movement's co-optation over the past three decades, all three authors also call for a reinvigorated feminism capable of withstanding the challenges posed by an ever encroaching neoliberal capitalism. It has been one of the central arguments of this paper that these alternative visions of a putatively progressive feminism, underdeveloped as they are, bias the tales of co-optation with which they are intertwined in 
ways that render them over-generalised and unconvincing. They effectively discipline feminism, first by differentiating its 'good' from its 'bad' elements, then by presenting both as separated from the left and finally, by marking only the former as worthy of resuscitation, if that is deemed possible. While we do not deny that some strands of feminism may in fact have been co-opted in conditions of neoliberalism, we have suggested here that the task of responding to the difficulties facing contemporary feminism requires the development of a more rigorous framework, replete with conceptual and empirical criteria, to help think through feminist possibilities. It is only with such a toolkit in hand that we can resist premature epitaphs about the death of feminism and begin the real work of reclaiming a progressive feminist future from the claws of a dangerous and destructive present.

\section{Notes}

1. Eisenstein also argues that liberal feminist arguments about women's lack of equality and sexual selfdetermination in Muslim countries have been enlisted in support of the War on Terror and its associated overseas interventions (2009, pp.169-196). In such ways, feminism in the US and beyond has become tied not only to 'capitalist globalisation', but also 'imperial domination' (2009, p.196).

2. See for example the influential paper by Mary Dietz (1987) or the response to Eisenstein by Johanna Brenner (2010).

3. In addition, as an anonymous reviewer of this paper has noted, this way of distinguishing socialism and feminism in Fraser and Eisenstein's texts could be interpreted as relying upon and reinscribing a dualism between class and gender and, in so doing, erasing a range of socialist and Marxist feminisms that seek to explore the interconnections of both. Connectedly, Fraser and Eisenstein seem to assume that socialism is a singular, unitary tradition rather than a heterogeneous political family with many strands within it. We thank the reviewer for these points, which deserve fuller exploration than we are able to give them here.

4. John Beverley, for instance, defines the left as 'the form of political and social agency that, in the name of the "people", would do away with capitalism and inaugurate a new mode of production' (1997, p.37).

5. The chapters in Pugh (2009) provide evidence of this tendency, with some notable exceptions (Colas and Edwards, 2009; McLellan, 2009).

6. By associating the left with the value of equality, Bobbio is not saying that adherents believe that everyone should be treated in exactly the same way or that they do not value difference and diversity among human beings and communities. As he makes clear, '[a]n egalitarian doctrine or movement which tends to reduce social inequality and make natural inequalities less painful is completely different from egalitarianism, understood as 'equality for everyone in everything' (1996, p.63). For Bobbio, what is fundamental to the left is the conviction that we are all equal in value and should be equally respected.

7. See, for example, the UK government's use of 'radicalisation' to describe the adoption of a more fundamentalist religious perspective among British muslim youth.

\section{References}

Alcoff, L. M. (2000) 'Who's Afraid of Identity Politics?', in Moya, P. M. L. \& Hames-García, M. R. (eds.) Reclaiming Identity: Realist Theory and the Predicament of Postmodernism. Berkeley: University of California Press, pp.312-343.

Benhabib, S. (1994) From Identity Politics to Social Feminism: A Plea for the Nineties [Online]. Available from: http://www.ed.uiuc.edu/eps/PES-Yearbook94 docs/BENHABIB.HTM [Accessed 21 January 2009].

Beverley, J. (1997) 'Does the Project of the Left have a Future?'. boundary 2, 24 (1): 35-57.

Bobbio, N. (1996) Left and Right: The Importance of a Political Distinction. Cambridge: Polity Press.

Bonnett, A. (2010) Left in the Past: Radicalism and the Politics of Nostalgia. New York and London: Continuum.

Brass, T. (2006) 'Subaltern Resistance and the ("Bad") Politics of Culture: A Response to John Beverley'. Journal of Peasant Studies, 33 (2): 304-344. 
Breines, W. (1989) Community and Organisation in the New Left, 1962-1968: The Great Refusal. New York: Rutgers University Press.

Brenner, J. (2010) 'Free-Market Feminism [Review of Eisenstein's Feminism Seduced]'. Monthly Review, 62 (7): 57-63.

Bruhn, D. A. (2005) 'Remodelling the Political Spectrum'. Politics [Online]. Available from: http://www.kuro5hin.org/story/2005/7/7/281/05051 [Accessed 11 May 2012].

Butler, J. (1998) 'Merely Cultural'. New Left Review, I (227): 33-44.

Chinchilla, N. S. (1991) 'Marxism, Feminism and the Struggle for Democrayc in Latin America'. Gender and Society, 5 (3): 291-310.

Cockburn, C. (2007) From Where We Stand: War, Women's Activism and Feminist Analysis. London: Zed Books.

Colas, A. \& Edwards, J. (2009) 'Democracy, The State and Capitalism Today', in Pugh, J. (ed.) What is Radical Politics Today. Basingstoke: Palgrave, pp.247-255.

Combahee River Collective (1977) The Combahee River Collective Statement [Online]. Available from: http://circuitous.org/scraps/combahee.html [Accessed 3/3/2009 2009].

De Sousa Santos, B. (2006) The Rise of the Global Left: The World Social Forum and Beyond. London: Zed Books.

Dean, J. (1996) Solidarity of Strangers: Feminism After Identity Politics. Berkeley and Los Angeles: University of California Press.

Dean, J. (2008) 'Feminist Purism and the Question of 'Radicality' in Contemporary Political Theory'. Contemporary Political Theory, 7 (3): 280-301.

Dean, J. (2009) 'Who's Afraid of Third Wave Feminism?: On the uses of the "third wave" in British feminist politics'. International Feminist Journal of Politics, 11 (3): 334-352.

Dean, J. (2010) 'Tormented Femininities [Review of McRobbie's The Aftermath of Feminism]'. NORANordic Journal of Feminist and Gender Research, 18 (2): 144-147.

Dietz, M. (1987) 'Context Is All: Feminism and Theories of Citizenship'. Daedelus, 116 (4): 1-24.

Eisenstein, H. (2005) 'A Dangerous Liaison? Feminism and Corporate Globalization'. Science and Society, 69 (3): 487-518.

Eisenstein, H. (2009) Feminism Seduced: How Global Elites use Women's Labor and Ideas the Exploit the World. Boulder and London: Paradigm Publishers.

Eisenstein, Z. (2007) Sexual Decoys: Gender, Race and War in Imperial Democracy. London: Zed Books.

Ellner, S. (2004) 'Leftist Goals and the Debate over Anti-Neoliberal Strategy in Latin America'. Science \& Society, 68 (1): 10-32.

England, K. V. L. (1994) 'Getting Personal: Reflexivity, Positionality, and Feminist Research.'. Professional Geographer, 46 (1): 80-89.

Fraser, N. (1995) 'From Redistribution to Recognition? Dilemmas of Justice in a "Postsocialist" Age'. New Left Review, I (212): 68-93.

Fraser, N. (2009) 'Feminism, Capitalism and the Cunning of History'. New Left Review, (56): 97-117. Giddens, A. (1994) Beyond Left and Right: The Future of Radical Politics Cambridge: Polity Press.

Gilbert, J. \& Littler, J. (2009) 'Radicalism: Strategies, Ecologies, Roots', in Pugh, J. (ed.) What is Radical Politics Today? Basingstoke: Palgrave Macmillan,

Henry, A. (2004) Not my Mother's Sister: Generational Conflict and Third-Wave Feminism. Bloomington: Indiana University Press.

Lang, S. (1997) 'The NGOization of Feminism: Institutionalization and Institution Building within the German Women's Movements', in Scott, J., Kaplan, C. \& Keates, D. (eds.) Transitions, Environments, Translations: Feminism in International Politics,. London: Routledge,

Lawson, G. (2005) 'Negotiated Revolutions: The Prospects for Radical Change in Contemporary World Politics'. Review of International Studies, 31 (3): 473-493. 
Loberfeld, B. (2004) The Real Meaning of Progressive Politics [Online]. Frontpagemagazine.com. Available from: http://archive.frontpagemag.com/readArticle.aspx?ARTID=11398 [Accessed 13 December 2011].

Lukes, S. (2003) 'Epilogue: The Grand Dichotomy of the Twentieth Century', in Ball, T. \& Bellamy, R. (eds.) The Cambridge History of Twentieth Century Political Thought. Cambridge: Cambridge University Press, pp.602-626.

Maiguashca, B. (2011) 'Looking Beyond the Spectacle: Social Movement Theory, Feminist Antiglobalization Activism and the Praxis of Principled Pragmatism'. Globalizations, 8 (4): 535 549.

Martin, B. (1997) 'Success and its Failures'. Differences: A Journal of Feminist Cultural Studies, 9 (3): 102-131.

Maxey, I. (1999) 'Beyond Boundaries? Activism, Academia, Reflexivity and Research'. Area, 31 (3): 199-208.

McLellan, G. (2009) 'Progressivism Reinvigorated', in Pugh, J. (ed.) What is Radical Politics Today? Basingstoke: Palgrave, pp.145-152.

McRobbie, A. (2004) 'Feminism and the Socialist Tradition ... Undone?'. Cultural Studies, 18 (4): 503 522.

McRobbie, A. (2009) The Aftermath of Feminism: Gender, Culture and Social Change. London: Sage.

Nussbaum, M. (1999) 'The Professor of Parody: The Hip Defeatism of Judith Butler'. The New Republic, 220 (8): 37-45.

Polletta, F. (2002) Freedom is an Endless Meeting: Democracy in American Social Movements. Chicago: University of Chicago Press.

Power, N. (2009) One-Dimensional Woman. London: Zero Books.

Pugh, J. (2009) What is Radical Politics Today? Basingstoke: Palgrave Macmillan.

Rose, G. (1997) 'Situating Knowledges: Positionalities, Reflexivities and Other Tactics'. Progress in Human Geography, 21 (3): 305-320.

Roseneil, S. (1995) Disarming Patriarchy: Feminism and Political Action at Greenham. Milton Keynes: Open University Press.

Snyder, R. C. (2008) 'What is Third Wave Feminism? A New Directions Essay'. Signs: A Journal of Women in Culture and Society, 34 (1): 175-196.

Taylor, V. \& Rupp, L. (2002) 'Loving Internationalism: The Emotion Culture of Transnational Women's Organizations, 1888-1945'. Mobilization, 7 (2): 141-158.

Thérien, J.-P. (2002) 'Debating Foreign Aid: Right versus Left'. Third World Quarterly, 23 (3): 449-466. van Zoonen, L. (2010) 'Brilliant and Compulsory Nostalgia [Review of McRobbie's The Aftermath of Feminism]'. European Journal of Women's Studies, 17 (2): 169-171.

Weber, C. (1994) 'Good Girls, Little Girls and Bad Girls: Male Paranoia in Robert Keohane's Critique of Feminist International Relations'. Millennium: Journal of International Studies, 23 (2): 337349.

Young, I. M. (1997) 'Unruly Categories: A Critique of Nancy Fraser's Dual Systems Theory'. New Left Review, I (222): 147-160. 